\title{
DA ETIQUETA AO DESEJO: O CASO TECNOBLU
}

\author{
Recebido em 20.11.2014. Aprovado em 03.12.2014 \\ Avaliado pelo sistema double blind review
}

DOI: http://dx.doi.org/10.12712/rpca.v8i4.511

\author{
Nilvane Boehm Manthey \\ nilvane_9@hotmail.com \\ Universidade do Vale do Itajaí - Santa Catarina - SC - Brasil
}

\section{Sidnei Vieira Marinho}

sidnei@univali.br

Universidade do Vale do Itajaí - Santa Catarina - SC - Brasil

\section{Anete Alberton}

anete@univali.br

Universidade do Vale do Itajaí - Santa Catarina - SC - Brasil

\begin{abstract}
Resumo
0 presente caso de ensino trata da Tecnoblu, empresa Catarinense fabricante de etiquetas, tags e lacres para o vestuário. Idealizada e fundada por Cristiano Buerger em 1994, transformou-se referência em tecnologia e inovação no segmento, tornando a etiqueta não só um produto de desejo, mas também um diferencial de comunicação para os produtos do vestuário. No entanto a trajetória da Tecnoblu é marcada por momentos decisivos, especialmente no ano de 2011, quando, apesar de apresentar resultados financeiros satisfatórios, depara-se com uma importante questão: Continuar atendendo a todos os públicos, mesmo aqueles que não têm interesse nos produtos diferenciados, ou focar nas marcas premium, aquelas marcas mais importantes do mercado e que anseiam por diferenciação? A análise dessas questões ocorre com o mapeamento das competências empreendedoras de Cristiano Buerger que proporcionaram o desenvolvimento das competências organizacionais da Tecnoblu.
\end{abstract}

Palavras-chave: Caso de Ensino. Competências Empreendedoras. Competências Organizacionais.

\begin{abstract}
This case deals with the teaching Tecnoblu, company Catarinense manufacturer of labels, tags and seals for clothing. Conceived and founded by Cristiano Buerger in 1994, became a reference in technology and innovation in the segment, making the label not only a product of desire, but also a differential communication for garment products. However the trajectory of Tecnoblu is marked by turning points, especially in 2011, when, despite a satisfactory financial results, is faced with an important question: Continue serving all audiences, even those who have no interest in the products differentiated, or focus on premium brands, those most important brands in the market and who yearn for differentiation? The analysis of these issues is the
\end{abstract}


mapping of the entrepreneurial skills of Cristiano Buerger developments that provided the organizational skills of Tecnoblu.

Keywords: Teaching Case. Entrepreneurial Skills. Organizational Skills.

\section{Introdução}

Naquela manhã de sexta-feira, Cristiano vai para a empresa bem cedo como de costume, entra em seu escritório e observa que Juliana, sua secretária, deixou os relatórios das atividades da empresa dos anos de 2010 e o parcial de 2011 que havia requisitado sobre sua mesa. Queria ter lido os relatórios antes, mas durante a semana esteve envolvido com os preparativos para participar de uma Feira de Design e Inovação de Componentes em São Paulo.

Cristiano pega os relatórios e senta no sofá, no entanto seus pensamentos não o permitem concentrar-se na leitura. Nesse momento Juliana entra na sala, e logo é indagada por Cristiano:

"-Juliana, estamos criando para quem?".

Surpresa pela pergunta, Juliana responde: “- Venho percebido sua introspecção há algum tempo Cristiano, imaginei que algo estivesse te preocupando. Só não entendi a sua pergunta: estás preocupado com a reunião de hoje?".

Cristiano pensa um minuto e responde: “- Não necessariamente com a reunião, mas com os rumos que nossa empresa irá seguir à partir das decisões que deverão ser tomadas: devemos permanecer atendendo de igual forma todos os nossos clientes, ou focar no público que realmente anseia pelo diferencial que nossos produtos oferecem?"

Juliana bem compreende o que Cristiano quer dizer, pois ao completar seus 17 anos de existência em 2011, a Tecnoblu, empresa Catarinense com sede em Blumenau, fabricante de etiquetas, tags e lacres diferenciados, dá sinais de que precisa adequar-se aos novos paradigmas que vive. Desde sua concepção, a Tecnoblu diferencia-se pela criatividade e inovação em seus produtos, e tem bons resultados no mercado. No entanto, todo o esforço em inovar, em diferenciar seus produtos não é atrativo a todos os seus clientes, pois muitos ainda querem o básico.

\section{De início um desafio!}

“- Sabe Juliana, eu entrei nesse ramo com 21 anos." Conta Cristiano Buerger, sócio fundador da Tecnoblu e Diretor de Inovação da empresa: "- Em 1990 eu cursava a faculdade de Comércio Exterior na Universidade Positivo, e era estagiário da Haco, líder em etiquetas no Brasil na época. No entanto, antes de concluir a faculdade, fui convidado pela Haco a mudar para o Rio de Janeiro. Olha... não foi fácil decidir, mas depois de refletir bem, resolvi abraçar, pois a empresa tinha um fábrica em Portugal, e meu plano era de trabalhar no exterior".

Juliana demonstra surpresa: "- Que interessante Cristiano, eu não sabia que você morou em Portugal!".

"-Na verdade não cheguei a ir." Responde Cristiano. "- Motivos pessoais me fizeram voltar para Blumenau em 1992. Aqui continuei trabalhando com etiquetas, como representante comercial de duas empresas".

“- Foi assim que surgiu a Tecnoblu?”. Indaga Juliana.

“- Exatamente! Como representante comercial notei que existia uma demanda, mas as fábricas não conseguiam entregar o produto. Vi uma oportunidade em um mercado que não estava sendo abastecido e resolvi abrir a minha empresa para atender esse mercado".

Cristiano para um momento olha pela janela do escritório de onde pode ver parte do pátio e das 
instalações da empresa e observa: “- Em 1994 eu era um jovem sonhador...” Neste momento Cristiano sorri ciente de que tal característica ainda o acompanha, e continua: "- Sempre tive muita força de vontade e obstinação, e com a experiência dos meus pais empresários, fundei a Tecnoblu. 0 nome surgiu da combinação de Blu, de Blumenau, com a metáfora Tecno, uma alusão à tecnologia, pois eu quis associar a empresa desde a sua origem, à inovação".

“- Certamente a Tecnoblu contribuiu muito para a mudança na concepção das etiquetas." Observa Juliana.

“- Sim Juliana, pois até aquele momento uma etiqueta, servia apenas para informar a marca, o preço ou o modo correto de lavagem de uma peça de roupa. Mas sempre tive em mente a necessidades de diferenciar meu produto, agregar algo novo". Reflete Cristiano, que continua:

“- 0 foco inicial era o mercado de Jenswear e o primeiro ano foi de crescimento rápido. A proposta de diferenciar-se no mercado, buscando novas possibilidades às etiquetas parecia que iria dar certo... mas aí veio a crise no Brasil e por pouco não fali."

Cristiano solta um suspiro e continua: “- A situação estava realmente complicada: em 1995 tive um índice de inadimplência de $76 \%$ e passei três anos viajando pelo Brasil como representante da Tecnoblu para pagar as dívidas, pois tivemos 161 títulos protestados só em 1995. Nesse período, a companhia ficou estagnada", recorda Buerger.

“-Mas Cristiano, não foi em 1996 o lançamento do nosso 1ํo mostruário de produtos?” Juliana indaga fazendo alusão ao Box Tendência da Tecnoblu, que viria a se tornar a principal ferramenta de venda dos representantes da empresa.

“-Sim Juliana. Sempre visualizei a importância da inovação, a necessidade de criar valor para o cliente, e mesmo em meio à crise, procurei esse diferencial para a empresa. Foi assim que deixamos de produzir commodities para investir em produtos de alto valor agregado." Cristiano baixa a cabeça, e a preocupação que por um momento havia esquecido, retorna: "- E agora me indago: Tanto esforço para inovar e diferenciar a Tecnoblu...mas para quem estamos inovando? Qual é o cliente que anseia pela inovação? É ele quem estamos atendendo?"

O silêncio se faz no escritório de Cristiano Buerger. Embora Juliana conheça bem a empresa para qual trabalha, prefere não opinar sobre o dilema de Cristiano e da Tecnoblu, pois sabe que a decisão sobre a que público focar as ações da empresa não pode ser tomado com base somente em números, especialmente por que no formato em que atende seu cliente está tendo excelentes resultados.

\section{Em busca de um diferencial}

"-Lembro que em busca de um diferencial para as etiquetas participei em uma feira na Europa, em 1999. Queria conhecer as tendências do mercado internacional. Assim, eu trouxe essas referências para o cenário brasileiro e lançamos o primeiro livro de tendências de etiquetas e tags". Fala Cristiano, referindo-se às etiquetas que ficam penduradas na roupa por uma cordinha.

“-Cristiano, é visível que a Tecnoblu está constantemente em busca de inovação. Mas também percebo forte ligação da Tecnoblu com o nosso país." Observa Juliana.

"-Sim Juliana. Mesmo antenado aos acontecimentos de fora do país, sempre buscamos reforçar os aspectos de brasilidade da Tecnob

Por isso à partir de 1999 passamos a contar com o trabalho de uma agência de publicidade, com intenção de alinhar a comunicação da nossa marca, fazendo alusão ao Brasil. Esse conceito foi adotado por carregar a ideia de diversidade e humanização, características inerentes da cultura 
brasileira, que também remete ao divertido e inusitado”. Explica Cristiano, e prossegue:

"-Seguindo esse propósito de identificação com o público, acrescentamos a marca Tecnoblu a tagline "Your ID", como forma de representar nossa missão que é a de entregar aos clientes, de forma confiável, soluções inovadoras que agreguem valor e personalizem suas marcas com identidade e funcionalidade. A tagline "Your ID" alinha as expectativas do público à exclusividade e personalização que a Tecnoblu se propõe, posicionando-se com relação aos concorrentes como uma empresa que foge ao tradicional...". Nesse momento, Cristiano é interrompido pelo toque do seu celular. Do outro lado da linha é Edmur Polli, seu sócio, ligando para confirmar presença na reunião. Cristiano desliga o telefone e Juliana indaga:

“-E o Sr. Edmur está na Tecnoblu desde o início?”

“-Não Juliana. Já tínhamos o escritório em São Paulo, no entanto os problemas relacionados à qualidade dos produtos e prazos de entrega me fizeram refletir a possibilidade de ter um sócio que me complementasse com outras habilidades. Assim, em 2004 Edmur, que é economista e engenheiro industrial, e com grande experiência na área fabril de empresas têxteis como Santista e Dudalina, passou a dividir comigo a administração da empresa".

Juliana observa: "-A criatividade e capacidade comercial do Senhor juntamente com a eficiência operacional do Sr. Edmur permitiram a formação de uma ótima dupla!".

“-Exatamente Juliana, em cinco anos conseguimos quadruplicar o faturamento da Tecnoblu." Exalta Cristiano. "Conseguimos transformar uma commodity em um produto de alto valor agregado!".

Juliana concorda: “-Sim, hoje, principalmente nos jeans e peças de maior valor, as etiquetas e tags vêm em diversos materiais, cores e texturas, servindo para reforçar a identidade da marca e dar personalidade à roupa. Os produtos podem também ser aproveitados para ações de marketing, transformando-se em porta-óculos e bolsas, dentre outras aplicações, e a Tecnoblu foi uma das responsáveis por essa mudança”.

Cristiano complementa: "-Um dos fatores mais importantes e que contribuíram a esta mudança significativa, foi a instituição, em 2007 do nosso E.T.” Cristiano faz alusão ao Estúdio de Criação Tecnoblu, composto por uma equipe multidisciplinar de pesquisa, para concepção de novas soluções e relacionamento com o mercado, com o objetivo principal de acompanhar tendências de moda e consumo, transportando-as para as coleções. O E.T. trouxe irreverência e inovação para a indústria de moda e design do Brasil, e é considerado o núcleo de inteligência criativa da empresa.

"-E a perspectiva de criação do E.T. para este ano é de 16 books temáticos, cada um com uma história diferente. Haja criatividade!” Observa Juliana.

“-É quando demonstramos nosso potencial criativo." Responde Cristiano. “-Esse ano serão 1,5 mil produtos inéditos lançados no mercado." Comemora Cristiano Buerger, que após uma breve pausa para reflexão observa: "-Sempre fomos inovadores em produto. Contudo, no mercado atual, somente isso não vale de nada. 0 importante é a empresa ser inovadora como um todo".

Novamente silêncio na sala de Cristiano. Juliana oferece um café para o chefe, que aceita. Cristiano toma o café enquanto Juliana fala:

“-Eu percebo a concentração de esforços para alinhar todo o ambiente organizacional aos preceitos da inovação, especialmente através das nossas políticas de desenvolvimento das pessoas. Acredito que foi por isso que fomos premiados esse ano com a Certificação de Responsabilidade Social, realizada pela Assembleia Legislativa do Estado, que além dos indicadores econômicos, sociais e ambientais, utiliza critérios estabelecidos pela própria 
Assembleia Legislativa para avaliar".

Cristiano complementa: "-Foi um reconhecimento aos nossos esforços em motivar as pessoas a buscar seu desenvolvimento pessoal e profissional, também por que acreditamos que tal atitude proporciona forte atração e retenção de talentos. Este ano são aproximadamente 230 colaboradores, e todos estão ligados ao nosso programa Formar para Sustentar".

"-Bom Cristiano, foi muito interessante conhecer mais detalhes da Tecnoblu, mas preciso organizar tudo para a reunião da tarde." Observa Juliana, saindo da sala.

Cristiano procura retomar a leitura dos relatórios na expectativa de encontrar a solução para o dilema da Tecnoblu. Neles encontra dados sobre a carteira de clientes da empresa que em 2011 chega a cerca de 800, e inclui marcas como Colcci, Forum, John John, Lacoste, Le Lis Blanc, Animale, Morena Rosa, M. Officer, Hering, Malwee, Riachuelo e Renner. A carteira de clientes está segmentada conforme demonstra a Figura 1.

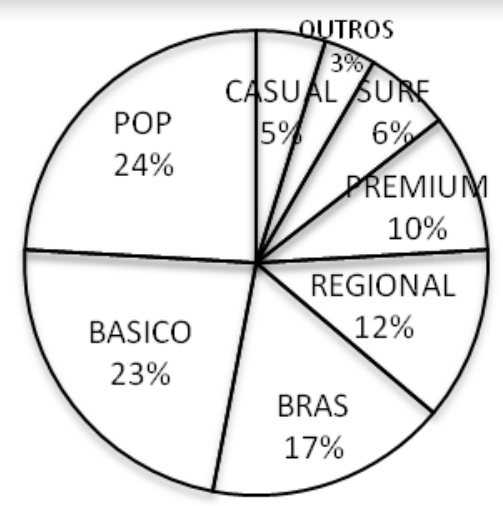

Figura 1: Percentual de vendas por segmento de mercado

Fonte: STEILL, V.; STEIN, M.. Brand Book Tecnoblu: Construindo um avião em pleno vôo. Disponível em: www.ngd.ufsc.br/files/2012/.../viviane monica vf-2.p

Cristiano observa que neste ano, em 2011, a Tecnoblu consolidou-se como empresa líder na criação de etiquetas e acessórios de moda e também pioneira no segmento de complementos decorativos na América. Seu faturamento é de $\mathrm{R} \$ 430$ milhões de reais ao ano, com a produção de 7 (sete) milhões de peças (etiquetas, tags, metais e botões); desse total, 4\% são exportadas.

Cristiano para a leitura do relatório por um momento e observa que Tecnoblu vai se tornando uma das companhias mais reconhecidas e antenadas do setor, tanto no Brasil quanto no exterior. Reflete sobre a importância das diversas ações paralelas às atividades da empresa como o Tecnoblu Note, um ciclo de palestras sobre tendências da moda, destinado a funcionários, estudantes e profissionais do ramo, trazendo referências para o mundo da moda e design. Cristiano lembra algumas das personalidades que já participaram do evento, como Renato Kherlakian, fundador da Zoomp, Alexandre Herchcovitch e Pedro Janot, ex-presidente da Zara no Brasil (o Tecnoblu Note é realizado em Blumenau desde 2000). Cristiano pensa nos seus esforços para realização do SCMC (Santa Catarina Moda Contemporânea), com o objetivo é fomentar o pensamento estratégico em inovação e design, integrando a comunidade acadêmica e o mercado, e que hoje é evento referência no Estado.

Cristiano reflete um tempo sobre a Figura 2 presente no relatório, e que apresenta alguns dos marcos para a Tecnoblu, pois demonstra o reconhecimento aos esforços da empresa em inovar e diferenciar-se. 


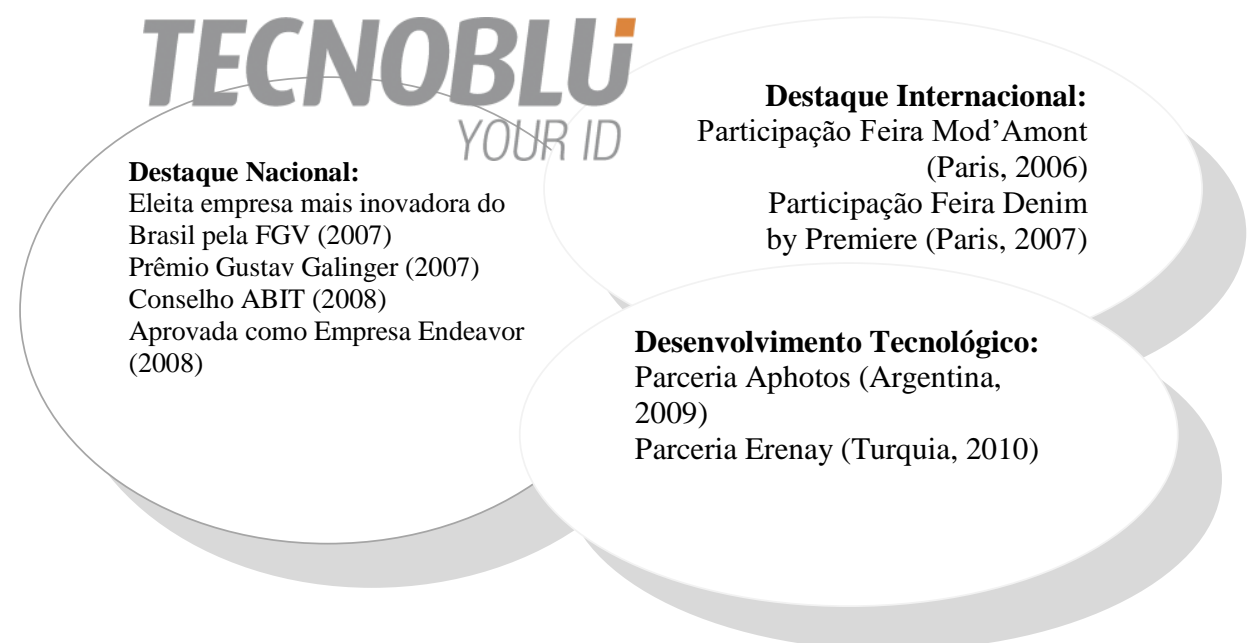

Figura 2: Marcos Históricos Tecnoblu

Fonte: TECNOBLU. Disponível em: http://www.tecnoblu.com.br/pt-br/.

Cristiano lembra a satisfação em ser a primeira empresa de aviamentos da América Latina convidada a participar das feiras Mod'Amont e Denim by Premiere em Paris, e o reconhecimento nacional com menções importantes no mercado brasileiro. 0 desenvolvimento tecnológico sempre foi o foco da Tecnoblu e as parcerias com a fabricante de produtos metálicos Aphotos, com a fabricante de lacres plásticos Erenay bem como a instituição da unidade de tear e a unidade gráfica possibilitaram ampliar seu mercado de atuação a um público cada vez mais exigente, fabricando etiquetas, emborrachados, galões, etiquetas tecidas e complementos metálicos. Todas essas ações foram essenciais para o desenvolvimento da Tecnoblu, e estão diretamente ligadas a sua essência, reconhece Cristiano.

Cristiano observa que aparentemente, tudo esta indo muito bem na Tecnoblu neste ano de 2011: o mercado se consolida, as vendas crescem, as políticas de gestão com pessoas dão resultados, o ingresso de um novo sócio, Sérgio Pires, colabora para o incremento de novas idéias. Mas para Cristiano Buerguer esse será um ano decisivo, um ano de ruptura interna ocasionada por um grande questionamento: "-Estamos criando para quem"?

Cristiano vê a manhã passar rapidamente, e logo mais, após o almoço, será a reunião com os sócios. Levanta-se e vai em direção ao refeitório da empresa. No caminho observa o negócio que sonhou e construiu com a ajuda de sua equipe, fica feliz com o que vê, mas sente a necessidade urgente de redirecionar as ações da empresa. Havia trocado algumas palavras sobre o assunto com seus sócios, Edmur e Sérgio, mas ainda não sabia exatamente o que pensavam sobre situação.

\section{A Reunião}

Na volta do almoço, dirige-se a sala de reuniões, onde Edmur Polli e Sérgio Pires já o aguardavam. Ao cumprimentarem-se, Edmur e Sérgio perceberam a expressão de preocupação em Cristiano.

“- E então Cristiano, o que nos traz a uma reunião na sexta-feira após o almoço?” Falou Sérgio Pires sorridente.

“-Uma pergunta que não gostaria de precisar fazer: Estamos criando para quem? Para deleite pessoal dos designers? Ou para atender a demanda do consumidor?" Cristiano indaga os sócios enquanto olha pela janela de vidro para as áreas internas da fábrica. A sala de reuniões ficava em frente ao Estúdio de Criação Tecnoblu, de onde se podia visualizar a equipe de criação, o cerne da Tecnoblu, trabalhando. 
“- Você já havia comentado comigo a percepção dessa necessidade.” Fala Sérgio Pires, e continua: "- Até o momento a Tecnoblu cria para todos os públicos, e embora estejamos conseguindo resultados financeiros em todos os segmentos, os nossos esforços em diferenciarnos, em inovar, em proporcionar a customização de nossos produtos aos clientes não interessa a todos. Os concorrentes já vêm atendendo o público geral, será que para manter-se competitivo a solução seria focar no segmento premium?"

Edmur Polli ressalta: “- As marcas premium são as melhores e mais importantes marcas do mercado, que até então não são contempladas."

Sérgio Pires observa: “-Para formar empresas sustentáveis e duradouras é preciso quebrar alguns pré-conceitos e criar produtos cada vez mais segmentados, de modo a produzir mais valor para o cliente final".

"-Fico aliviado em perceber que vocês também sentem essa lacuna entre nosso produto e as expectativas dos clientes!" Comenta Cristiano, que observa: “-A Tecnoblu tornou a etiqueta não só um produto de desejo, mas também um diferencial de comunicação para os produtos do vestuário, tornando-se referência a nível nacional".

Cristiano apresenta uma pesquisa presente no relatório, que analisa a imagem da marca junto aos stakeholders da Tecnoblu listando os principais concorrentes nacionais e internacionais da empresa, (Hacco (SC-Brasil), Helvetia (SP, Brasil), Okinawa (Milão, Italia), Reca Group (Milão, Itália)). A pesquisa leva em consideração dois atributos: inovação na comunicação da marca e tradição na comunicação da marca, originando o mapa de percepção apresentado na Figura 3.

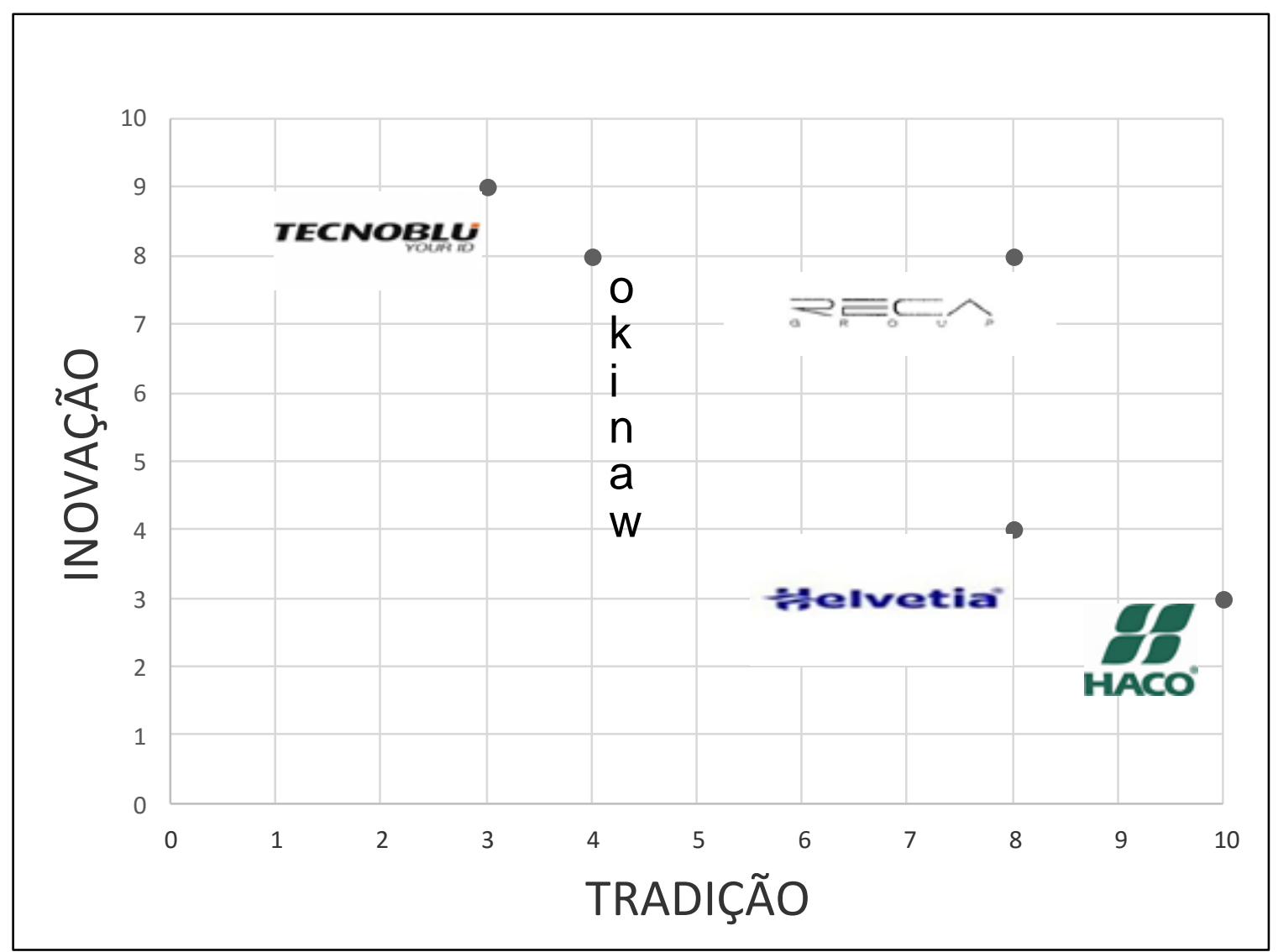

Figura 3: Mapa de Percepção/Concorrentes.

Fonte: STEILL, V.; STEIN, M.. Brand Book Tecnoblu: Construindo um avião em pleno vôo. Disponível em: www.ngd.ufsc.br/files/2012/.../viviane_monica_vf-2.p 
“- A Tecnoblu é considerada pelos stakeholders, a marca nacional mais inovadora, seus atributos se aproximam da italiana Okinawa. No mercado nacional ela se destaca pela imagem de inovadora enquanto os concorrentes mais importantes, Haco (80 anos) e Helvetia (75 anos), exploram uma imagem de tradicionalismo. 0 posicionamento adotado pela Tecnoblu favorece 0 alcance de nossa missão." Observa Cristiano.

0 trio de empresários ficou horas na sala de reuniões a conversar sobre o dilema atual: Focar sua atenção ao segmento premium? Que ações da empresa direcionavam a esse caminho? A solução ficou para a reunião posterior, pois sentiam a necessidade de pensar melhor sobre a trajetória da empresa, especialmente sobre as competências empresariais que a Tecnoblu desenvolveu ao longo de sua história e que a diferenciaram de seus concorrentes.

\section{Notas de Ensino}

\section{Posicionamento do Caso}

As informações contidas no caso foram idealizadas para a utilização em cursos de graduação e pós-graduação em Administração de Empresas, Gestão e MBA nas disciplinas de Empreendedorismo e Estratégia. Optou-se por trabalhar questões pertinentes às competências do empreendedor e competências organizacionais que possibilitem a criação de vantagem competitiva.

No entanto, o caso permite o desenvolvimento de reflexão em outras áreas de atividade empresarial: em Estratégia com o estudo da RBV (Visão Baseada em Recursos) (BARNEY et.al., 2001) e da estratégia competitiva (PORTER, 1999); em Marketing com a análise da orientação para o cliente (KOTLER, 2000) e o modelo das cinco forças competitivas (PORTER, 1999); em Estratégias de Internacionalização, com a reflexão sobre os modos de entrada (CARNEIRO; DIB, 2007) e alianças estratégicas com a utilização de competição internacional com produtos inovadores e intensos em tecnologia (MARIOTO, 2007); e Criatividade e Inovação, com o estudo de fundamentos e processo de inovação e o papel da liderança (TIDD et.al., 2005).

\section{Objetivos Educacionais}

Pretende-se desenvolver nos participantes:

(1) Familiaridade com o ambiente empresarial (aspectos externos e internos à organização);

(2) Respostas cognitivas e emocionais quanto a esta realidade;

(3) 0 estudo e crítica da literatura sobre empreendedorismo, gestão de competências organizacionais, criatividade e inovação e gestão de mudanças organizacionais;

(4) Análise reflexiva e busca de estratégias para resolução do caso, bem como aplicação em situações do cotidiano do aluno.

\section{Fontes de Dados}

O caso foi escrito com base em fontes secundárias, sendo as principais o site da empresa, o balanço social, revistas, artigos e trabalhos acadêmicos disponibilizados em meios eletrônicos. 


\section{Tópicos Pedagógicos}

A proposta de estudo do caso pode ser organizada da seguinte forma:

a) Leitura e análise individual por aluno antes da aula;

b) Análise e discussão do caso em pequenos grupos na sala de aula à luz da teoria (tempo sugerido 1 hora);

c) Discussão em sessão plenária, orquestrada pelo professor.

d) Fechamento da discussão através da criação do mapa de competências do perfil empreendedor do Cristiano Buerger e das competências organizacionais da Tecnoblu, (conforme apresentado nos quadros 2, 4 e 5 das notas de ensino).

\section{Questões para discussão}

As questões apresentadas foram desenvolvidas visando estimular junto aos estudantes a reflexão, de forma a melhor estruturar o problema e produzir uma resposta mais analítica do que descritiva. Dentre as perguntas mais relevantes, que poderiam ser formuladas aos alunos, sugerem-se:

1) 0 que são competências? Quais as competências características do empreendedor? Como as competências do empreendedor podem influenciar a empresa?

2) Definir o perfil empreendedor do fundador da empresa (competências empreendedoras) que possibilitaram o desenvolvimento da Tecnoblu.

3) 0 que são competências organizacionais? Porque as competências organizacionais são importantes na formação de vantagem competitiva empresarial?

4) Avalie quais as competências organizacionais, que possibilitaram a origem da vantagem competitiva da empresa.

5) Com base na análise de competências, você como gestor da Tecnoblu focaria o desenvolvimento de seus produtos a um público que anseia por inovação (premium), ou permaneceria atendendo a todos os segmentos de mercado?

\section{Análise do caso e conexão com a literatura}

A temática a ser discutida no caso trata das competências, especificamente as teorias/abordagens que explicam sobre as competências do empreendedor e competências organizacionais.

\section{Resposta das Questões 1 e 2}

David McClelland foi o primeiro a propor o conceito de competência de forma estruturada em 1973, na procura por uma abordagem mais efetiva que os testes de inteligência na busca de pessoas para as organizações. O conceito foi rapidamente ampliado para dar suporte a processos de avaliação e ações de desenvolvimento profissional, e conta com ajuda de Boyatzis (1982) para estruturação de um conceito que procura fixar ações ou comportamentos efetivos esperados a partir das demandas de determinado cargo na organização (DUTRA, 2004).

Para definir o termo competência, utiliza-se o conceito dos autores citados no Quadro 1. 


\begin{tabular}{|c|l|}
\hline AUTOR & \multicolumn{1}{c|}{ CONCEITO } \\
\hline Rhinesmith & $\begin{array}{l}\text { Competência é a capacidade específica de executar a ação em um nível de } \\
\text { habilidade que seja suficiente para alcançar o efeito desejado. }\end{array}$ \\
\hline Fleury & $\begin{array}{l}\text { Competência é o saber agir responsável e reconhecido, que implica } \\
\text { mobilizar, integrar, transferir conhecimentos, recursos, habilidades que } \\
\text { agreguem valor econômico á organização e valor social ao indivíduo. }\end{array}$ \\
\hline Mirabile & $\begin{array}{l}\text { Competência é um conjunto de conhecimento, habilidade, aptidão ou } \\
\text { características associadas com alta performance no trabalho, como } \\
\text { resolução de problemas, pensamento analítico ou liderança. }\end{array}$ \\
\hline Levy-Leboyer & $\begin{array}{l}\text { Competência é o repertório de comportamentos e capacitações que } \\
\text { algumas pessoas ou organizações dominam melhor que as outras, } \\
\text { fazendo-as eficazes em uma determinada situação. }\end{array}$ \\
\hline
\end{tabular}

Quadro 1 : Conceito de competência.

Fonte: Vergara (2000, p.38); Dutra, (2004, p.24); Hanaschiro, (2007, p.217); Gramigna, (2002, p.15).

Para Leme (2006) embora as definições de competência sejam diferentes, a essência permanece a mesma: conhecimento, habilidade e atitude. 0 autor divide as competências em dois grupos: competências técnicas e competências comportamentais. "[...] A competência técnica é tudo o que o profissional precisa saber para desempenhar sua função. [...] A competência comportamental é tudo que o profissional precisa demonstrar como seu diferencial competitivo e tem impacto em seus resultados" (LEME, 2006, p.14).

Leme (2006) faz a integração entre o conhecimento, habilidades e atitude e as competências técnicas e comportamentais, onde o conhecimento (saber) e as habilidades (saber fazer) referem-se às competências técnicas, e a atitude (querer fazer) refere-se à competência comportamental. À luz da teoria de LEME (2006), observou-se o perfil das competências de Cristiano Buerger relacionado a seu desenvolvimento empreendedor, visualizado no Quadro 2.

\begin{tabular}{|c|l|}
\hline COMPETÊNCIAS & \multicolumn{1}{|c|}{ PERFIL DE CRISTIANO BUERGER } \\
\hline $\begin{array}{c}\text { TÉCNICAS: CONHECIMENTOS (SABER) } \\
\text { E HABILIDADES (SABER FAZER) }\end{array}$ & $\begin{array}{l}\text {-Conhecimento de negócios: Pais empreendedores, } \\
\text { possibilitando vivência empresarial. } \\
\text {-Conhecimento do ramo: Se apresentam através da } \\
\text { experiência de } 3 \text { anos na área de vendas da Haco e de outras } \\
\text { duas empresas fabricante de etiquetas. }\end{array}$ \\
\hline & $\begin{array}{l}\text {-Diante da visualização da oportunidade, abriu sua empresa, } \\
\text { buscando diferenciação ao longo de sua trajetória. } \\
\text {-Em meio à crise, trabalhou como representante da } \\
\text { empresa, acreditando na possibilidade de crescimento. } \\
\text { COMPORTAMENTAIS: ATITUDE } \\
\text { (QUERER FAZER) } \\
\text { conhecimento a necessidade de diferenciação, buscou } \\
\text {-Desenvolveu projetos na internacional. } \\
\text { da empresa (Tecnoblu Note e SCMC). }\end{array}$ \\
\hline
\end{tabular}

Quadro 2 : Competências observadas no perfil de Cristiano Buerger.

Fonte: Adaptado de Leme (2006, p.14).

Para observar as competências do empreendedor é pertinente resgatar o conceito de empreendedorismo a fim de situar o ambiente em que o empreendedor se desenvolve. 0 
conceito de empreendedorismo pode ser visualizado na Quadro 3.

\begin{tabular}{|c|c|}
\hline AUTOR & CONCEITO \\
\hline BARON; SHANE (2010) & $\begin{array}{c}\text { O empreendedorismo, como atividade executada por indivíduos } \\
\text { específicos envolve ações-chave de identificar oportunidade } \\
\text { potencialmente valiosa que possa ser explorada como um negócio e } \\
\text { identificar as atividades envolvidas na exploração ou no desenvolvimento } \\
\text { real dessa oportunidade, bem como a capacidade de administrar esse novo } \\
\text { negócio com sucesso após a criação. }\end{array}$ \\
\hline DORNELAS (2011) & $\begin{array}{l}\text { Empreendedorismo é o envolvimento de pessoas e processos que, em } \\
\text { conjunto, levam à transformação de ideias em oportunidades. }\end{array}$ \\
\hline
\end{tabular}

Quadro 3: Conceito de empreendedorismo.

Fonte: Baron; Shane (2010) e Dornelas (2011).

O empreendedor, além de ser o idealizador e fundador da empresa, em muitos casos, também é o gestor. A Figura 4 demonstra as competências inerentes gestor organizacional segundo Hanaschiro (2006).

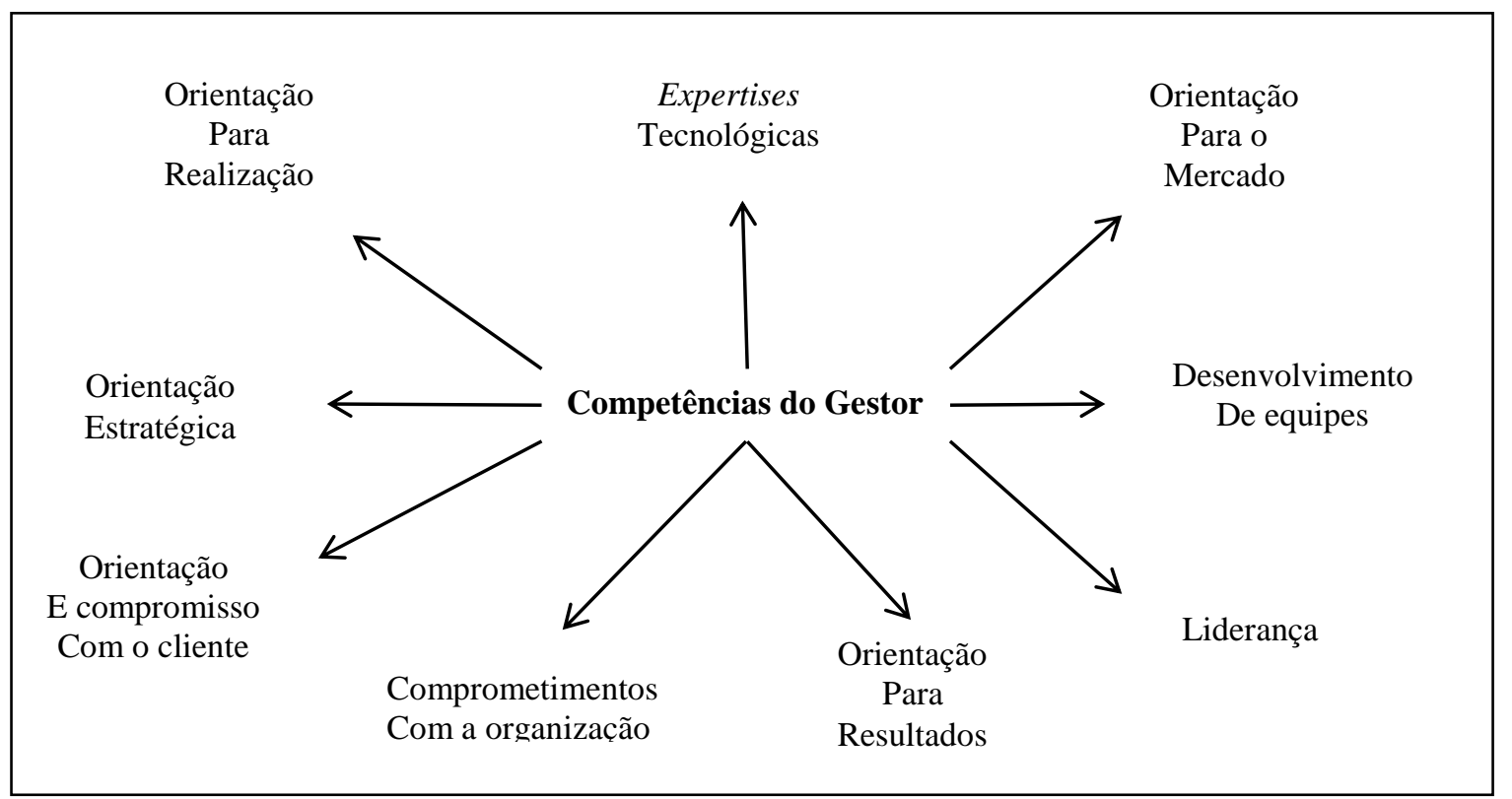

Figura 4: Competênci

as do Gestor.

Fonte: Hanaschiro (2006).

As competências características do empreendedor, com base nos estudos de Man e Lau (2000), são categorizadas em seis áreas distintas de comportamento, quais sejam: competência de oportunidade, de relacionamento, conceituais, administrativas, estratégicas e de comprometimento. 0 Quadro 4 apresenta as competências do empreendedor, segundo MAN e LAU (2000) e o observado no perfil de Cristiano Buerger. 


\begin{tabular}{|c|c|}
\hline COMPETÊNCIAS EMPREENDEDOR & PERFIL CRISTIANO BUERGER \\
\hline $\begin{array}{l}\text { OPORTUNIDADE: } \\
\text { avaliação e busca de oportunidade de } \\
\text { mercado }\end{array}$ & $\begin{array}{l}\text { Identificou a lacuna deixada pelos fabricantes de etiquetas } \\
\text { no mercado Brasileiro. Buscou nova oportunidade através } \\
\text { da diferenciação de seus produtos. }\end{array}$ \\
\hline $\begin{array}{ll}\text { RELACIONAMENTO: } & \text { Networking } \\
\text { (desenvolver e aproveitar). } & \end{array}$ & $\begin{array}{l}\text { Criação e participação em feiras e eventos (Tecnoblu Note, } \\
\text { SCMC, Premiére Vision, Mon'amout...) }\end{array}$ \\
\hline $\begin{array}{l}\text { CONCEITUAIS: Observadores tanto das } \\
\text { oportunidades do ambiente externo } \\
\text { quanto dos aspectos internos da } \\
\text { organização. }\end{array}$ & $\begin{array}{l}\text { Inovou em um produto que aparentemente não necessitava } \\
\text { de inovação (ambiente externo). } \\
\text { Criação do Estúdio de Criação Tecnoblu para acompanhar e } \\
\text { desenvolver tendências (ambiente interno) }\end{array}$ \\
\hline $\begin{array}{l}\text { GERENCIAIS: } \text { Mecanismos de } \\
\text { planejamento, organização, comando, } \\
\text { motivação, delegação e controle de } \\
\text { recursos físicos, financeiros, } \\
\text { tecnológicos e alocação de talentos. }\end{array}$ & $\begin{array}{l}\text { Cristiano reconheceu sua dificuldade em algumas } \\
\text { competências gerenciais, e foi buscar sócios que o } \\
\text { complementassem nesse sentido (Edmur Polli e Sérgio } \\
\text { Pires). Mas antes do primeiro ingressar na Tecnoblu, esta já } \\
\text { havia formulado a estratégia principal da Tecnoblu: } \\
\text { diferenciar-se em produto através da inovação. }\end{array}$ \\
\hline $\begin{array}{l}\text { VISÃO DE MERCADO: Escolha e } \\
\text { implementação das estratégias da } \\
\text { empresa no curto e longo prazo. }\end{array}$ & $\begin{array}{l}\text { Cristiano buscou os mecanismos de desenvolvimento e } \\
\text { manutenção da estratégia empresarial desde o início da } \\
\text { empresa. A reavaliação de estratégias conforme } \\
\text { apresentado no dilema identifica a preocupação no longo } \\
\text { prazo. }\end{array}$ \\
\hline $\begin{array}{l}\text { COMPROMETIMENTO: Habilidade de } \\
\text { manter a dedicação do dirigente ao } \\
\text { negócio, sobretudo em situações } \\
\text { adversas. }\end{array}$ & $\begin{array}{l}\text { Esta competência fica evidente quando, mesmo enfrentando } \\
\text { as adversidades da crise no Brasil, Cristiano não desistiu de } \\
\text { sua ideia, de sua empresa. }\end{array}$ \\
\hline
\end{tabular}

Quadro 4 : Análise das competências do empreendedor no perfil de Cristiano Buerger.

Fonte: Adapatado de Man; Lau (2000).

Observa-se que do empreendedor necessita de uma postura pró-ativa para agir de maneira satisfatória na criação e desenvolvimento de negócios. Portanto, as competências de um empreendedor não se restringem tão somente á competências gerenciais. No entanto, ao comparar-se os estudos de Hanaschiro (2006) sobre competências dos gestores e Man e Lau (2000) sobre as competências do empreendedor, podemos observa-se que as competências necessárias para empreendedores e para gestores assemelham-se e complementam-se.

Ruas (2005) analisa a influência das competências do empreendedor/gestor para o desenvolvimento empresarial observando que o gestor realiza o potencial de resultados, de pessoas e de inovação da organização fazendo a ligação entre a empresa e as pessoas que nela trabalham, sendo responsável pela composição de forças e interesses. Neste contexto, Ruas (2005) avalia a importância das competências do gestor empresarial, ressaltando que gestores/líderes tem o papel de criar ambientes organizacionais que inspirem, suportem e alavanquem a imaginação e a iniciativa que existe em todos os níveis organizacionais.

As competências do gestor, além de constituir uma instância fundamental nos processos de mudança tendo em vista o papel da liderança, também exercem importante função na mobilização de outras dimensões das competências organizacionais: essenciais (âmbito da organização como um todo), funcionais (áreas da empresa e grupos) e individuais (FLEURY, 2001, p.247). 


\section{Resposta das Questões 3 e 4}

O assunto competência no âmbito organizacional aparece associado à competitividade e vantagem competitiva: "algo que confere competitividade a uma organização e é um fator que desempenha relevante influência dentre os componentes de uma fonte de vantagem competitiva" (HANASCHIRO, 2007, p.216). "0 domínio de determinadas competências faz com que profissionais e organizações façam diferença no mercado” (GRAMIGNA, 2002, p.15).

Competência organizacional é o resultado de uma combinação estratégica de recursos, habilidades e processos organizacionais, os quais são orientados e integrados para o atendimento de uma ou mais necessidades dos clientes; e que em virtude de suas propriedades únicas, contribui de forma relevante para a geração de valor e para a formação de vantagem competitiva sustentável (HANASCHIRO, 2007, p.217).

Hanaschiro (2007) explica que as competências organizacionais não ocorrerem de forma aleatória, e nem são intermitentes. "Adquirem perfil sistemático e comportamento consistente, ao longo do tempo, por serem incorporadas aos processos e rotinas organizacionais. Em decorrência, caracterizam-se pela durabilidade e perfil de longo prazo" (HANASCHIRO, 2007, p.217).

Aos conhecimentos, habilidades e atitudes que constituem as competências organizacionais, Ruas (2005) denomina de recursos de competências, pois, segundo o autor, são essenciais para o desenvolvimento das mesmas. Ruas (2005) cita o desdobramento desses recursos de competências como: conhecimentos (gerais e teóricos, operacionais e sobre o ambiente), saberfazer (operacional, experimental e relacional cognitivo), atitudes (atributos pessoais e relacionais) e recursos do ambiente (sistemas de informação e bancos de dados), ressaltando que esses recursos mobilizados geram o desempenho organizacional.

Dutra (2004) propõe categorias distintas de competências organizacionais: competências essenciais, competências distintivas, competências de unidades de negócio, competências de suporte e competências de capacidade dinâmica. A definição de cada competência, bem como o observado através do caso que é desenvolvido na empresa Tecnoblu está relacionado no Quadro 5 .

\begin{tabular}{|c|c|}
\hline $\begin{array}{c}\text { CATEGORIAS DE COMPETÊNCIAS } \\
\text { ORGANIZACIONAIS }\end{array}$ & DESENVOLVIDO NA EMPRESA TECNOBLU \\
\hline $\begin{array}{l}\text { COMPETÊNCIAS } \\
\text { Fundamentais para a sobrevivência da } \\
\text { organização e centrais em sua estratégia. }\end{array}$ & $\begin{array}{l}\mathrm{Na} \text { Tecnoblu, pode-se inferir que as competências } \\
\text { essenciais são estão relacionadas à tecnologia e inovação } \\
\text { que permitem a diferenciação de seu produto. }\end{array}$ \\
\hline $\begin{array}{l}\text { COMPETÊNCIAS } \\
\text { Reconhecidas pelos clientes como } \\
\text { diferenciais em relação aos competidores, } \\
\text { conferem a organização vantagens } \\
\text { competitivas. }\end{array}$ & $\begin{array}{l}\text { Essas competências estão relacionadas a possibilidade de } \\
\text { personalização das marcas dos clientes que a Tecnoblu } \\
\text { proporciona, utilizando-se de materiais diversos. } \\
\text { Relaciona-se também à inovação. }\end{array}$ \\
\hline
\end{tabular}




\begin{tabular}{|l|l|l|}
\hline $\begin{array}{l}\text { COMPETÊNCIAS DE UNIDADES DE } \\
\text { NEGÓCIO: Pequeno número de } \\
\text { atividades-chave (entre três e seis) } \\
\text { esperadas pela organização das unidades } \\
\text { de negócio. }\end{array}$ & $\begin{array}{l}\text { Para identificação dessas competências seria importante } \\
\text { um estudo mais apurados das unidades de negócio da } \\
\text { empresa. As passíveis de serem identificadas no caso são } \\
\text { as Competências-chave do Estúdio Tecnoblu - } \\
\text { identificação de tendências; criação de design de produtos; } \\
\text { desenvolvimento de novos produtos. }\end{array}$ \\
\hline $\begin{array}{l}\text { COMPETÊNCIAS DE SUPORTE: } \\
\text { Atividades que servem de alicerce para } \\
\text { outras atividades da organização. }\end{array}$ & $\begin{array}{l}\text { Está relacionado à àrea de vendas, atendimento ao cliente } \\
\text { (SAC), área de gestão com pessoas, onde mais } \\
\text { especificamente nesta observa-se preocupação em seu } \\
\text { desenvolvimento através dos programas do "Formar para } \\
\text { Sustentar". }\end{array}$ \\
\hline $\begin{array}{l}\text { CAPACIDADE DINÂMICA: Condição da } \\
\text { organização de adaptar continuamente } \\
\text { suas competências as exigências do do } \\
\text { ambiente. }\end{array}$ & $\begin{array}{l}\text { A Tecnoblu está atento ao seu ambiente, prova disso é } \\
\text { visualizada através da parceria com Aphotos e Erenay, e } \\
\text { instituição das unidades gráficas e de tear, que visam } \\
\text { melhorar e desenvolver novos produtos no mercado. }\end{array}$ \\
\end{tabular}

Quadro 5: Categorias de competências desenvolvidas na empresa Tecnoblu.

Fonte: Adaptado de Dutra (2004).

Hanaschiro (2007) salienta que as competências organizacionais adquirem significado para os funcionários justamente por serem compostas por conjuntos de competências individuais, e por isso promovem o compromisso, permanecendo estáveis ao longo do tempo, estabelecendo elo entre estratégia e ação e dificilmente serão copiadas pelos concorrentes.

Podemos entender que as competências organizacionais são fontes de vantagem competitiva sustentável e que dentro delas encontramos as competências individuais que são difíceis de imitar. Estudam-se as competências individuais para garantir a vantagem competitiva organizacional por meio das pessoas (HANASCHIRO, 2007, p.218).

Ruas (2005) discorre que na instância corporativa e sob forma de competência coletiva, a competência organizacional é associada aos elementos da estratégia competitiva da organização: visão, missão e interação estratégica, como está sucinto na Figura 5. 


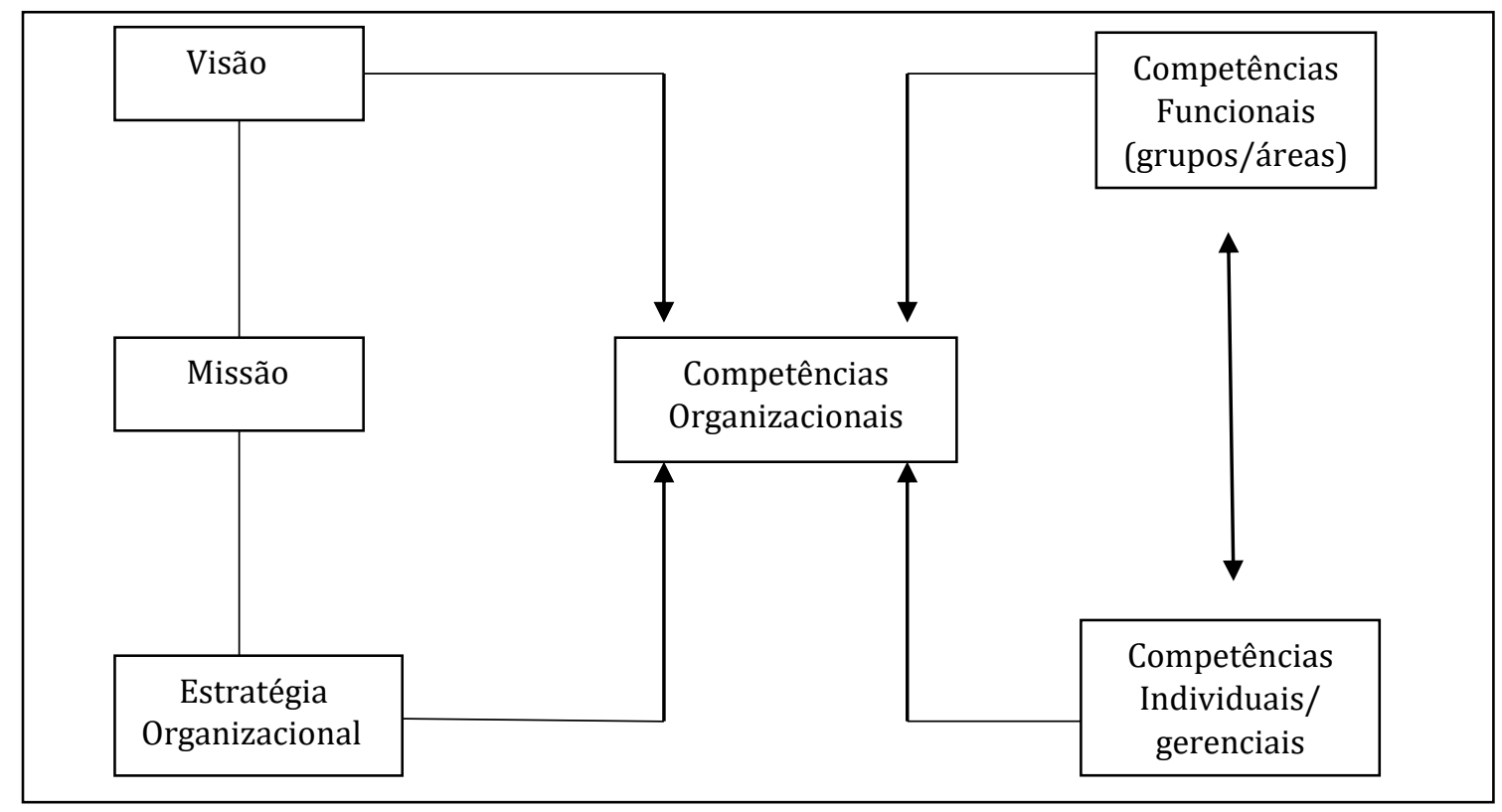

Figura 5: Configuração organizacional da noção de competência Fonte: Ruas (2005, p.42)

Partindo do pressuposto do entendimento de que as empresas são comunidades sociais cujo principal papel é administrar seu conhecimento de forma mais eficiente que os seus competidores, Zarifian (2001) afirma que o conhecimento é a base das competências essenciais da empresa, onde competências essenciais "são o conjunto de habilidades e tecnologias que habilitam uma companhia a proporcionar um benefício particular para os clientes, mais do que uma habilidade ou tecnologia isoladamente" (ZARIFIAN, 2001, p.126).

\begin{abstract}
As organizações que aprendem, dedicadas a constante melhoria do processo, sistemas, produtos e da qualidade dos recursos humanos, estimulam o surgimento de novas habilidades que são incorporadas nas competências coletivas. Sem o processo de aprendizado, qualquer combinação de competências eventualmente pode se tornar antiquada, possibilitando que as vantagens competitivas da empresa sejam rapidamente copiadas pelos rivais (HANASCHIRO, 2007, p.230).
\end{abstract}

Com estes conceitos pode-se perceber que há vários elementos interligados e que constituem um importante processo que direciona a organização a obtenção de vantagens competitivas sustentáveis. As habilidades e capacidades individuais e o ambiente organizacional favorável são fatores de alavancagem de competências organizacionais, pois "por meio de condições necessárias para a apropriação e internalização de conhecimentos e habilidades, amplia-se o repertório de respostas e de maneiras de ser e agir (competências) associando-se a novos princípios e práticas de gestão" (FLEURY, 2001, p. 253).

\title{
Resposta da Questão 5
}

Para conduzir a resposta da Questão 5 em sala de aula, é importante o professor salientar que não existe resposta certa ou errada, existem caminhos diferentes, devendo-se, portanto, estimular o aluno a procurar diferentes soluções, a partir da análise e discussão, estimulando a motivação, a participação ativa e a transferência de aprendizagem. (IKEDA et.al. 2005).

Para responder os autores tomaram como base a decisão da empresa Tecnoblu em consonância com a teoria observada por Gramigna (2002) e Fleury; Fleury (2004).

0 dilema vivenciado pela Tecnoblu ocasiona um momento de ruptura interno, provocado pelo 
questionamento: “Estamos criando para quem?". Desde então, a Tecnoblu passou a produzir apenas para o mercado premium para atender segmentos diferentes que, até então, não eram contemplados. Hoje, a empresa investe em linhas voltadas para o casual, o esportivo e, principalmente, para o fast fashion. (SCMC, 2013).

A Tecnoblu acredita que para formar empresas sustentáveis e duradouras é preciso quebrar alguns pré-conceitos e criar produtos cada vez mais segmentados, de modo a produzir mais valor para o cliente final. (ENDEAVOR, 2014). Tal posicionamento vai de encontro às ações que a empresa desenvolve desde sua criação em busca de inovação e tecnologia, e que foram constituintes de suas competências essenciais. As competências essenciais devem estar alinhadas às estratégias organizacionais, para que possam efetivamente criar vantagem competitiva. (FLEURY; FLEURY, 2004).

Gramigna (2002) observa que o elemento base para a sobrevivência das empresas no mundo atual são as competências essenciais, pois tornam possível um diferencial no mercado.

\footnotetext{
O investimento prévio em uma competência essencial não é um salto no escuro, nem uma grande aposta no desconhecido. 0 que impulsiona o processo de desenvolvimento é o desejo de liderança mundial na provisão de um benefício fundamental para o cliente. As competências mais valiosas são as que abrem as portas para uma grande variedade de possíveis mercados (GRAMIGNA, 2002, p.54).
}

Quando a competência essencial está localizada em Pesquisa e Desenvolvimento, como é o caso da Tecnoblu (que ocorreu principalmente por intermédio da institucionalização do E.T. - estúdio de criação), as empresas passam a competir por produtos inovadores e neste caso a estratégia indicada é a orientação para clientes. (FLEURY; FLEURY, 2004).

A orientação para clientes caracteriza-se quando a empresa volta-se para "as necessidades de clientes específicos, individualizados, procurando se especializar no desenvolvimento de produtos, sistemas e soluções que atendam as suas demandas atuais e futuras". (FLEURY; FLEURY, 2004). A Tecnoblu demonstra ter consciência do diferencial que o desenvolvimento de competências essenciais pode proporcionar especialmente para empresas que trabalham a nível mundial e que pretendem expandir seu negócio.

\section{Referências}

BARON, Robert A.; SHANE, Scott A. Empreendedorismo: uma visão do processo. 2a ed.São Paulo: Cengage Learning, 2010.

BARNEY, J; WRIGHT, M; KETCHEN, D. The resource-based view of the firm: Ten years after 1991. Journal of Management. vol. 27 no. 6 625-641. December 2001.

CARNEIR0, J.; DIB, L. A. Avaliação Comparativa do Escopo Descritivo e Explanatório dos Principais Modelos de Internacionalização de Empresas. . INTERNEXT - Revista Eletrônica de Negócios Internacionais da ESPM, São Paulo, v. 2, n. 1, p. 1-25, jan./jun. 2007.

DORNELAS, J. C. Empreendedorismo: Transformando idéias em negócios. São Paulo: Campus, 2011.

DUTRA, Joel Souza. Competências: conceitos e instrumentos para a gestão de pessoas na empresa moderna. São Paulo: Atlas, 2004. 
ENDEAVOR. Disponível em: www.endeavor.org.br/empreendedor/cristiano-buerger. Acesso em: 05/03/2014.

FLEURY, M. T. L.; OLIVEIRA Jr., MIRANDA, Moacir. Gestão Estratégica do conhecimento: integrando aprendizagem, conhecimento e competências. São Paulo: Atlas, 2001.

FLEURY; A.; FLEURY; M. T. Estratégias Empresariais e formação de Competências: Um caleidoscópio da Indústria brasileira. São Paulo: Atlas; 3ํed. 2004.

GRAMIGNA, Maria Rita. Modelo de competências e gestão dos talentos. São Paulo: Makron Books, 2002.

HANASCHIRO, D., TEIXEIRA, M., ZACCARELLI, L. Gestão do fator humano: uma visão baseada em Stakeholders. São Paulo: Saraiva, 2007.

IKEDA, A. A.; VELUDO DE OLIVEIRA, T. M.; CAMPOMAR, M. C. 0 caso como Estratégia de Ensino de Administração. Revista de Administração, São Paulo, v.41, p.147-157, abr./mai./jun. 2006.

KOTLER, P. Administração de Marketing. 10aㅡ Ed..Tradução Bazán Tecnologia e Lingüística; revisão técnica Arão Sapiro. São Paulo: Prentice Hall, 2000.

LEME, Rogério. Aplicação prática de gestão de pessoas por competências. Rio de Janeiro: Qualitymark, 2006.

MAN ,T. W. Y.; LAU, T. Entrepreneurial competencies of SME owner/manager in the Hong Kong services sector: a qualitative analysis. Journal of Enterprising Culture, v. 8 ,n. 3, 2000.

MARIOTTO, P.P. et.al. Estratégia Internacional da Empresa. São Paulo: Thomson Learning, 2007.

PORTER, M. Competição = On Competition: Estratégias Competitivas Essenciais. Trad. Afonso C. da Cunha Serra. 13ª ed. Rio de Janeiro: Elsevier, 1999.

RUAS, R. L.; ANTONELLI, C. S.; BOFF, L. H. Os novos horizontes da gestão: aprendizagem organizacional e competências. Porto Alegre: Bookman, 2005.

SCMC. Experience Tecnoblu - insight sobre o futuro da moda brasileira. Disponível em http://www.scmc.com.br/site/blog/tag/tecnoblu/. Setembro, 2013.

STEILL, Viviane; STEIN, Mônica. Brand Book Tecnoblu: Construindo um avião em pleno vôo. Disponível em: www.ngd.ufsc.br/files/2012/.../viviane monica vf-2.p

TECNOBLU. Disponível em: http://www.tecnoblu.com.br/pt-br/. Acesso em 02/03/2014.

TIDD, J.; BESSANT, J.; PAVITT, K. Gestão da Inovação. 3ª ed. Porto Alegre: Bookman, 2005.

VERGARA, Sylvia Constant. Gestão de Pessoas. São Paulo: Atlas, 2000

ZARIFIAN, Philippe. Objetivo Competência:por uma nova lógica. São Paulo: Atlas, 2001. 
